\title{
CREDIT ANALYSIS OF THE BANKING SECTOR
}

\section{UMANG PASARI}

Symbiosis Institute of International Business (SIIB), Symbiosis International University (SIU), Hinjewadi, Pune, Maharashtra State, India

\begin{abstract}
Credit Analysis of Banking Sector curating upon the study of the defaulted Organizations IL\&FS, DHFL and Yes Bank which has created a fiasco in the economy and has affected all the stake holders related to the organizations and the economy. Non-availability of data related to the organizations credit analysis and non-payment and disclosures under the IND-AS and Companies Act. The poor management and faulty disclosures or non-disclosures of various parameters led to the default of the system. Mis-Management of the Directors and the inter-relatedness of the organizations with respect to their loan books and credit systems have led to the default. The Fundamental Analysis has been widely used and references to annual reports have been of immense help. The default has caused a set back and will take back time to gain confidence towards NBFC's and Private Banks.

KEYWORDS: Credit, Analysis, Banking, Default, NBFC, Rating
\end{abstract}

Received: Jun 08, 2020; Accepted: Jun 28, 2020; Published: Sep 16, 2020; Paper Id.: IJMPERDJUN20201282

\section{INTRODUCTION}

The root or the chronicled backdrop in the structure of Banking in our countryis followed with foundation of Bank in 1786. The Banking in the country starts in most recent decade which is eighteenth century with the establishment of English Agency houses in various parts of the country. Around at that point, Banking system was simply made sure about that urban people and need of commonplace and agriculture section was totally dismissed. Regardless, the beauty of the Post-Independence Phase from the time self-governance, the entire Banking portion was under private ownership. The common people of the country expected to dependent on little money credit pros for their necessities. To appreciate these problems and better progress of economy, Government of our country nationalized the RBI in 1949. Soon the Imperial Bank was given national status and was named as the State Bank of India. Through the beginning of Nationalization Period in 1969, Indian Government nationalized 14 immense banks with national wealth were in excess of 50 crores.

Presently to reveal a touch of insight into the NBFCs they started unassumingly in India during 1960s as a possibility for liberators and examiners of whom money related requirements were not satisfactorily met by the current monetary structure. NBFCs from the outset took a shot at an obliged ranking without having a great deal of impact on the budgetary business. They invited fixed stores from monetary masters and worked out leasing can hope for enormous present-day firms. During principal periods the progression, Companies Act oversaw funding. In any case, the exceptional and complex nature of errands and with cash related associations going about as budgetary representatives, there was a require an alternate managerial framework. Similarly, Chapter III B is associated with the Reserve Bank of India Act, which designated the Bank with confined experts towards control store earnings associations. From here on out the RBI has begun measures to deal with the NBFC section. 
During the 1990's and between 1980's, NBFCs, had a huge client hearted influence, started to pull in unlimited scholars. The measure of NBFCs rose quickly from an unimportant 7000 of each 1981 to around 30000 out of 1992 , which made the RBI need to control the business. In the year 1997 in January there was a colossal change in the central bank's act, particularly in a few of the chapters in the Act planning a set up a total definitive, administrative structure, which would ensure about interest in addition guarantee the smooth working of NBFC. After modification of the Act in 1997, the NBFCs have become all around with respect to works out, degree of instruments and market things, inventive advancement, between others. Over most recent 20 years, NBFCs has gotten perceptible quality and given significance to money related area. In 2016, the affiliation agency offered the thumbs up for outside direct undertaking (FDI) receiving the changed course in managed NBFCs. NBFCs go about as a move up to banks by offering structure to appropriate overabundance focal points for people and relationship with deficiencies. NBFCs comparably fill the extra need of presenting dispute in budgetary associations. Not in the smallest degree like banks which offer a bundled bargain on a huge amount of money related associations, NBFC offers redo associations to suit the particular needs of customers NBFCs expanding down to business contribution with one express division develop an educational good position.

From advances, credit workplaces to personal tutoring subsidizing and retirement arranging, from trading money markets and ensuring equity and offers, and Term Certificates, institutions offer for all intents and purposes all banking organizations. Providing wealth the board organizations like regulating stocks and offers portfolios, restricting organizations like constraining instruments and offer direction on merger and acquisitions exercises.

Going to the most significant part which is Credit Analysis it is a kind of analysis a financial specialist or bond portfolio chief performs on organizations or other obligation giving substances to quantify the element's capacity to meet its obligation commitments. The credit analysis looks to recognize the fitting degree of default risk related with putting resources into that specific substance. It is additionally a technique to decide the believability of the organization and the gaining capacity of the organization. The result of the credit analysis will figure out what risk rating to allot the obligation guarantor or borrower.

To pass judgment on an organization's capacity to pay its obligation, banks, bond speculators, and examiners lead credit analysis on the organization. Utilizing money related proportions, income analysis, pattern analysis, and monetary projections, an expert can assess a company's capacity to pay its commitments. A survey of credit scores and any insurance is additionally used to ascertain the creditworthiness of a business.

The result of the credit analysis will figure out what risk rating to appoint the obligation backer or borrower. The risk rating, thus, decides if to stretch out credit or loan cash to the obtaining substance and, provided that this is true, the sum to loan. By distinguishing organizations that are going to encounter an adjustment in the red rating, a financial specialist or chief can hypothesize on that change and potentially make a profit.

\section{LITERATURE REVIEW}

RanadevGoswami 'and S. Venkatesh have analyzed Credit rating, as a moderately new idea in the Indian monetary market, that had expanded wide affirmation among financial specialists. Simultaneously, easygoing and episodic proof proposes that there are worries among speculators and regulators about the display of rating workplaces in India. They found a high dispersion of rating utilization among all class of financial specialists, however there was a discernible disillusionment with dependability of ratings, affinity of resulting minimizing and idealness of rating reconnaissance. They 
found a high scattering of rating usage among all class of financial specialists, however there was a detectable embitterment with unwavering quality of appraisals, penchant of resulting downsizing and practicality of rating observation. Their review additionally uncovers that the institutional speculators have predominant information and comprehension about evaluations than singular financial specialists. Subsequently, the review underlines the requirement for rating organizations to chip away at instructing the regular financial specialists to proliferate legitimate comprehension and utilization of credit score.

Mrs. Rosy Kalra made an attempt to analyze the fact that NBFCs have picked up prevalence in the ongoing occasions. They work to offer updated esteem value and risk-based things and offer fund to various divisions in the economy. NBFCs are creating as a particular alternative for regular banking. Besides, NBFCS are in like manner ascending as fundamental piece of Indian Financial System and they have outstanding duties to the Government's inspiration to cash related Inclusion. They have been fruitful to a degree by offering credit to retail clients in locales where individuals don't have bank accounts. Numerous such borrowers assume praise from NBFCs and throughout the years utilize their exhibition record with NBFCs and experience to end up bankable borrowers. They are today experiencing an incredibly critical stage where Reserve Bank of India has furnished a surveyed administrative structure with an objective to synchronize it with banks and Financial Institutions and address administrative holes and exchange. In this manner, it gets the chance to be fundamental to examine the presentation analysis of NBFCs and break down it.

Srinivas Gumparthi SSn Non-banking financial companies (NBFCs) structure an essential piece of the Indian financial system. The historical backdrop of the NBFC Industry in India is an account of under-guideline followed by overguideline. Strategy producers have swung starting with one extraordinary position then onto the next in their endeavor to set controls and afterward limit them so they don't check the development of the business. This report covers the business. The greater part of this current NBFCs' are working with high risk of loaning and all the more frequently NBFCs' loan credit to SMSE, which are sorted as high-risk class of Assets. To survey such high-risk resources, we have to have an extensive model. This paper point is to construct Risk Assessment Model for NBFCs depends on both subjective and quantitative parts of the customer.

Y.V.Reddy has given a overview of credit rating, and agencies engaged with such rating, both local and global. The advantages expected and reactions leveled will likewise be reviewed. The principle focal point of the location would be the issues identifying with sovereign rating and utilization of credit rating by controllers, particularly in the banking area. From the Reserve Bank of India's immediate concern, the subject must be seen as far as sovereign rating of India, rating of States in India and the utilization of rating in managing financial establishments, for example, banks and NonBank Financial Companies (NBFCs) just as instruments, for example, Commercial Paper (CP); this not the slightest bit brings down the significance of rating for corporates. It must be noticed that the accentuation here is on the utilization of rating in the administrative structure, particularly of the RBI and not on directing credit rating offices, which is completely in the locale of SEBI.

Amita S. Kantawala based on the investigation, he has reasoned that there exists a noteworthy contrast in the profitability ratios, leverage ratios and liquidity ratios of different classes of NBFCs. At the point when two classifications are inspected against one another, at that point the more noteworthy number of ratios are not measurably not quite the same as one another in larger part of the cases aside from where TS+IH are contrasted and renting. At the point when all classifications are taken together, invalid theory is acknowledged for just three ratios showing in this manner that there 
doesn't exist a critical contrast in just three ratios. From this it follows that the ratios for all classifications of NBFCs are commonly not quite the same as one another. The investigation of change alongside the insights regarding normal ratios may turn into a valuable manual for companies to choose about enhancement or continuation in a similar line of business thinking about by and large profitability inside the administrative structure. To sum things up, various classifications of NBFCs carry on distinctively and it is the business visionary's decision in the light of conduct of some the boundaries which oblige the classification of NBFC.

G.Vairava Subramanian, Dr. S. Nehru exclaims that SMEs are essential piece of India's development story. SMEs contribute not exclusively to the residential market yet in addition to sends out altogether, in this way procuring remote exchange income for the nation, accordingly causing the sector to rise as extremely solid column in India both as far as GDP and as far as work. Today SMEs are contributing more than 16-18\% of Indian GDP and if this sector is getting more help, the sector can undoubtedly contribute over $30 \%$ to the GDP. The greatest test for SMEs in India is, groundbreaking money related administration both for running of the affiliation similarly with respect to augmentation practices taking in to thought the overall contention. Raising resources from money related establishments like banks, NBFCs for SMEs are till date a significant test. It is evaluated that solitary $16 \%$ of Indian SME part have been given bank/foundations support and the rest of the segment can't get support. The essential clarification behind these lacunae is, not having successful administration devices set up, absence of information on banking rules, incapable component to gauge the credit value of the organization. The current situation of Indian economy is pushing RBI, to get an exacting loaning strategy because of stoppage in development, which has influenced the loaning strategy to be increasingly moderate with high financing cost, which is obviously upsetting the reality to be determined sheets of SMEs. This in the long run become progressively hard for SMEs, for their development plan as well as to make the organization to run in troublesome circumstance, when the economy is in hinder mode, in this way convincing this endeavor to remain in on level as far as development or even perform lower than earlier years, not at all like other greater corporate which develops quickly in light of their solid measures and backing from the banking sector. Other piece of the story is, Bankers are a long ways behind in loaning rules set somewhere around RBI, corresponding to SME sector, the greatest test for Banking sector is, there is no legitimate instrument, dissimilar to greater corporates to quantify the nature of the association as far as resource quality, IP(intellectual properties) and the business through acclaimed private organizations. So as to guarantee that the banking system enters the SME space more and simultaneously, applies alert regarding resource quality, the system of SME rating got presented. In this article, we will dissect all the data identified with SME rating, why it is vital? advantages of rating for SMEs and banking sector, Industry development openings because of rating system, challenges looked by SMEs because of rating system, future development of SME sector and so forth.

K.S. Venkateswara Kumar; S. Hanumantha Rao Credit rating business is a specialty section in the financial administrations field. In the post-changes period, with expanded movement in the Indian Financial sector both existing and new companies are choosing money from the capital market. The opposition among firms for a cut of the reserve funds cake has expanded. Credit rating business in India is a sweet spot for what it's worth on the cusp of hearty development potential, driven by three triggers: Strong capex cycle in Indian economy, lower infiltration of corporate security showcase and administrative push because of execution of Basel II norms. Credit rating helps in the improvement of financial markets. Credit rating is a financial specialist administration and a rating organization is required to keep up the most noteworthy conceivable degree of scientific ability and uprightness. The investigative structure of rating manages assessment of both the business and financial risks related with that substance. Other than subjective perspectives like 
management abilities likewise assume an impressive job in deciding a rating. Credit ratings set up a connection between risk and return. They consequently give a measuring stick against which to quantify the risk innate in any instrument. Logical structure of rating manages assessment of both the business and financial risks related with that element. The Reserve Bank of India liaises with SEBI, on the issue of rating organizations' adherence to IOSCO Code of Conduct Fundamentals. Given the droop looked by economies all-inclusive and the ascent in the quantity of defaulters, the time has come for the channel had a solid credit rating system set up to guarantee smooth activity for the whole chain. The most noteworthy change in ongoing identifies with accentuation on their responsibility and increasingly significant, the alert in controllers' utilization of ratings.

VijayaKittu Manda, P. Sai Rani has supervised that one-fifth credit of the nation, the NBFC's is an essential zone for the economy. Development of issues is harming Indian NBFC area since the default of structure support major IL\&FS in 2018. Which appeared, apparently, to be liquidity emergency is moving nearer into a dissolvability situation. Some significant stakeholders bolstered being accepted marketing specialists are leaving profession. Regardless of the way that the minimizations and defaults do widely impact the banking and store industry when in doubt, there is palatable out of control situation inciting disrupting impact in express area in the business. Housing Finance Companies and the Asset Management Industry viewed as feeble and got fundamentally hurt by emergency. A focal issue that instigated the liquidity issues in the business is the piece of breathing space hazard tangle. Controllers incline toward tweaking gigantic extension cash related factors to decrease the issue as opposed to giving an exceptional liquidity window. The emergency incorporated the essential for significantly closer affiliation and the trade between controllers to excuse such prospects of future attacking the air pockets so that these could wind up at ground zero to change into a primary hazard. Disclosures from the paper can be of immense help to different associates from the NBFC, the controllers, and the Government in better status.

\section{METHODOLOGY}

The method used in this research paper is exploratory research where in the existing literature related to the topic is studied. The existing literature has been reviewed and the gaps are identified. The methodology used is Secondary Research Methodology. There will be use of more of qualitative data for the analysis. Data related to the company's financials and market performance on various indices would come handy in the process of analysis. Data collected from Annual reports of companies for previous 5 years of IL\&FS, DHFL and Yes Bank. Share Prices from National Indices would utilize for the objectives of the paper. These would help me reach to the desired objectives of the Research Paper and reach a proper conclusion.

\section{RESULT AND ANALYSIS}

Credit Analysis of Infrastructure Leasing \& Financial Services (IL\&FS), Dewan Housing Finance Corporation (DHFL) and Yes Bank are covered as a part of the research in the study. The findings are from the fundamental analysis of the companies of the year of their defaults and the quarters when their results were affected due to the effect of their false reporting of their financials and faulty disclosures from their board of directors. Which resulted in the loss of all the stakeholders related to the organization. The auditors also have commented on various issues related to the organizations working and this ultimately resulted in reveal of the defaulting situations of the organizations. The study also shows how the defaulters were interlinked and have posed threat to various other organizations indirectly. 
The results and findings from the fundamental analysis of IL\&FS showed that the auditor's opinions that the financials were not clean and major discrepancies are present in the Annual Report of the organization. The findings include comments on various parameters mentioned. Non accounting of interest income and interest expense from the organization for the year ended 2018-19 which was questionable. Pending fulfillment of inward review of budget reports of different auxiliaries, partners, joint endeavors and so on. Besides, the Audit confirmations on different boundaries where not got, for example, Reconciliation of contrasts with one bank where not referenced in the financials which questioned on the reimbursement of the loans to the bank. Unreconciled contrasts in BRS where left untraced and unmentioned. Unfit on the premise that the organization doesn't have data required by Schedule III of Companies Act 2013 and certain guidelines by RBI in full exposures. The evaluators questioned on the materiality ideas and the going concern ideas for the associations confidence as the organization had caused loss of • 2,25,272.53 million for the year finishing March 31, 2019 and the different offices had minimized the association in credit ratings to 'D' since 2018. The organization didn't have the essential and complete data to help income-based tests over its ventures, and suspicions over specific parts of the normal credit misfortune concerning loans and receivables. The organization has not represented legally binding interest salary from its auxiliaries, partners and Joint endeavors of approx. INR 7000 million and legally payable fund costs on borrowings of approx. INR 6900 million. Review proof was not gotten for: Reconciliation of contrasts with one bank to the going with independent fiscal summaries adding up to around INR 2400 million (which the board accepts speaks to an unapproved alteration made by the bank in the organization's bank account). Unreconciled differences in bank reconciliation statements or borrowings includes a direct debit by banks of approx. INR 1400 million. The management says it arose on account of claims of penal interest. Direct confirmation from three banks with respect to derivatives of INR 337 million. The Board of Directors are liable for managing the Company's monetary detailing process and have likewise not remarked on their exhibitions in their Directors Report.

The outcomes situated towards DHFL have additionally been inferred out of Fundamental Analysis that the Financials brought to the partners are unseemly on different boundaries and have caused devotion in question and broken revelations to all the partners of the association. The organization's administration is to blame in worry to the working of the association and are the prime worry towards the issues with respect to the broken working of the association. The discoveries incorporate that The Unsecured Inter-Corporate Deposits (ICD) extraordinary as on March, 2019 conglomerating Rs. 5.6 lakhs. Conveyed in the note, there are tremendous deficiencies in the respect and rollover of ICD, between alia, non-accessibility of assessment of credit estimation of the borrowers, business procedure for intuition encompassing explanation of allowing of the ICD. The note besides conveys that the Company is progressing toward remediating these inadequacies and that no adjustment is required to the passing on respect thereof. There has not been given adequate fitting review proof to help the association's assessment and starting now and into the foreseeable future can't assess on the recoverability of the ICD and the noteworthy impact on the Statement. In regard of express credits and Pass-through Certificates (PTC) gathering Rs. 32 lakhs and Rs. 25 thousand lakhs, autonomously, allowed or contributed by the Company during the year and in prior years and important as at March 31, 2019. As conveyed in the Statement, distinctive bookkeeping regions were from the start recorded in certain client addresses receipts in spite of the checks or asking to be refuted instrument not been kept in the bank(s) and these have been in this way traded. The gross estimation of such advances hard and fast Rs. 16.48 lakhs.

Analysts didn't get agreeable data and clarifications to our enquiries identifying with credit, legitimate and specific examination and proof for end use checking as conveyed in the improvement understanding and exhibited by the 
Finance Committee, any place material, in regard of experience advances and home advance pushes gathering Rs. 24.07 lakhs. The association had chosen for measure moves signifying Rs. 31.62 lakhs (unites certain advances gathering Rs. 26.62 lakh) and PTC gathering Rs. 25 thousand lakhs at Fair Value Through Profit or Loss (FVTPL) considering inside valuations which consolidate the heads' judgment and suppositions. there has been not been given agreeable fitting overview check and the entire of the critical data and clarifications in regard of the reasonable quality's movements of Rs. 3 lakhs (gross of inversion obviously of activity) and Rs. 6 thousand lakhs so observed on the advances, PTCsolely.

Since there has not been satisfactory information the evaluators couldn't get sufficient legitimate survey evidence to help the estimations of the advances and PTC and we can't choose whether these issues would influence the Statement consolidating as for any adjustments as per the passing on estimation of the credits and Certificates, reiteration, connected occasions, various presentations and consent as fitting.

Information on Deferred Tax Assets were also undisclosed on the Annual Reports the Company had seen net surrendered charge asset of Rs. 44 thousand lakhs as at March, 2019. The Company requires to play give assessment as prescribed in Ind AS 12 - 'Individual Taxes' which requires the Company to choose the probability of future accessible compensation to utilize the surrendered charge asset. In any case, there has not been given satisfactory reasonable confirmation to favour the Company's assessment about the passing on estimation of the surrendered charge asset and significant adjustments required, expecting any, to the Statement. the Company has achieved use conglomerating Rs. 10,401 lakhs for improvement of changed programming for its tasks and recording of exchanges which has been passed on as unclear resource being gone after as at March 31, 2019. The Company has not played out an obstruction assessment as required by Ind AS 36 - 'Impedance of Assets' which requires the Company to pick if the cash related ideal situation in regard of this irrelevant resource will be available to the Company in coming about periods thinking about the shortcoming in regard of its course of action to change its focal points, secure supporting from the delegates/budgetary specialists, patch up its liabilities and recommence its activities. Thinking about prior, we have not been given adequate fitting affirmation about the passing on estimation of the immaterial resource being managed and changes required, tolerating any, to the Statement.

The Company has realized shortage hoarding Rs.1.03 lakhsin the yearand current liabilities of Rs. 75.4 thousand lakhs as at March 2019. Further, the organizations FICO score been reduced to 'default grade' coming to fruition to the end of the year which might basically incapacitate its capacity to increase or make assets for reimburse its obligations. The issues portrayed in addition affect the Company's capacity to proceed as a going concern. These updates raise a fundamental weakness on the restriction of the Company to proceed as a going concern and ultimately, it might be not prepared to appreciate its central focuses and conveyance its liabilities recalling expected liabilities for the normal course of business. The Company is changing its great conditions and has acquainted a draft target course of action with the consortium of budgetary authorities for altering its borrowings and additionally there have been conversations for stake deal by the backers to a key assemble as one with further worth imbuement. The constraint of the Company to proceed as a going concern spread alia is destitute upon its capacity to alter its focal points, secure supporting from the mediators or cash related specialists, adjust its liabilities and recommence its activities, which are less inside Companies Control. In this way, Going Concern andMateriality Concepts are addressed.

The Yes Bank disaster has its own centrality in the more than two affiliations. The account of the bank is undeniably a story in solitude. The organizations credit books on March 2014, was Rs 55.6 crores, and stores were Rs 74.1 
crores. Beginning now and into the not so distant, the advancement book has made to pretty much four-cover the entirety, at Rs 2.25 trillion as at September2019. Whereas store improvement neglects to keep up and reached out at under different events to Rs 2 trillion. The organizations preferred position quality in like way declined and it went under controller RBI's scanner. Without a doubt, Bank had a liberal prologue for two or three bombshell debtors, together with the Anil Ambanidrove Reliance party, DHFL and IL\&FS. The topping point came when one of the bank's autonomous managers Uttam Prakash Agarwal, left the board in January 2020 implying association discrepancies. A couple of purposes for the emergency at the new-age private-region bank were as: Yes Bank ran into trouble following the national bank's favoured position quality surveys in 2017 and 2018, which incited a sharp enlargement in its crippled credits degree and revealed essential association sneaks past that affected a total difference in the board. The bank thusly battled to address its capitalization issues. Truth be told, Bank continued on through an energizing copying in its gross NPAs among April and September 2019 to Rs 17.134 crores. The emergency in India's shadow-banking space began with the disentangling of IL\&FS and a brief timeframe later released up to Dewan Housing Finance Limited (DHFL). YES Bank's immovable prologue to IL\&FS and DHFL was 11.5 percent as of September 2019. In April 2019, the bank had planned about Rs 10,000 crore of its presentations, tending to 4.1 percent of its rigid credits under watch list, as potential non-performing advances all through the going with a year.

YES Bank faced two or three organizations gives that induced its decay. On January 10, free manager Uttam Prakash Agarwal quit suggesting deteriorating corporate organization rules and consistence disappointment at the moneylender. In 2018-19, the organization under-pronounced NPAs to the tune of Rs 3.27 crores, impelling RBI to dispatch R Gandhi, one of its past agent lead delegates, to the principle social affair of the bank. Rana Kapoor, who was instrumental in building YES Bank with no arranging, was moved nearer to resign as CEO in early 2019.

YES Bank's money related condition kept various investors from keeping resources in the bank over a more drawn out term. The bank showed a predictable withdrawal of stores, which upset its bookkeeping report and added to its difficulties. The bank had a store book of Rs 2.09 trillion around the completion of September 2019.

Bringing about RBI assuming control over the organization's Management and the banking controller, while recommending a ban, alluded to a steady diminishing in YES Bank's money related position, fundamentally as a result of the loan expert's inability to raise adequate income to make game plans for potential non-performing assets. This missing the mark realized minimizations by FICO score workplaces, which along these lines made capital raising altogether more inconvenient. This isolated, there were dead serious slips in corporate administration at the bank.

RBI also tried to see the interconnectedness between Yes Bank and non-banking financial companies (NBFCs) against the backdrop of the IL\&FS, DHFL crisis. Yes Bank disclosed an exposure of Rs 2 thousand crores to IL\&FS, which is currently standard on the bank's books. The bank also has $3.2 \%$ of its loan book exposed to housing finance companies and $2.6 \%$ to NBFCs.

Since September 2019, both banking and markets regulators have been looking at the spillover effect of the payment defaults by IL\&FS and its group companies, this paved path to liquidity shortage in the banking system. This was followed by the abrupt sale of Dewan Housing bonds held by DSP Mutual Fund for a loss, fearing redemption pressures. 
The Securities and Exchange Board of India has also gathered information from mutual funds regarding their show castto NBFCs and housing finance companies. The mutual fund industry cumulatively held securities worth Rs 2 thousand crores sold by IL\&FS and its related entities.

In September, RBI dismissed the bank's proposition to broaden Kapoor's term as the CEO and set a cutoff time of 31 January to discover a replacement. This was trailed by numerous ways out by board individuals, including those of Ashok Chawla and R. Chandrashekar.

Thus, the interconnectedness is yet to be discovered as a whole, however the NBFC's and the banks inter relatedness has been of harm to the stakeholders and the country as a whole and has to be looked upon. The findings also show that the Banks and NBFC's should have a complete disclosure or there should be stricter norms to look into the functioning at regular intervals.

\section{CONCLUSIONS}

India was in the midst of a tri balance sheet emergency, spread across banks, corporates and NBFC's due to the emergency of IL\&FS, DHFL, and Yes Bank. The shadow banking emergency that launched out in mid-2018 had made an immense credit pound structure causing various defaulters and various broken accomplices around the country. That therefore set off contamination not simply in the cash related economy, which remained vivaciously introduced to shadow banks, yet notwithstanding pockets of the certifiable economy like land and smaller scale, little and medium endeavours which depended upon humble financing through shadow banks to continue their development. Post the IL\&FS crisis, numerous skeletons began exposing the unadulterated truth and raised more ruckus. What's more, it became known that the loans given by Yes Bank clearly didn't turn terrible short-term. The pressure fired showing up step by step until 2018, when the loan specialist confronted a gigantic blow and could not repay the loans taken. NPA's rose and hence curated out to be a massive blow, Yes Bank individually had 3.23 billion \$ NPA's. This has created a major issue around with all the stakeholders and the economy and has trapped the confidence over private banks and NBFC's.

\section{RECOMMENDATIONS}

In the research the cause for failures of the organizations has been covered and how it affected the stakeholders. It is recommended for the future researchers to include more information related to the interdependency between the organizations for a clearer picture of the crisis created in the country and the economy. More in-depth research would be required to connect the organizations.

\section{REFERENCES}

1. Anand Sinha Monthly March , Regulation of Shadow Banking - Issues and Challenges https://rbidocs.rbi.org.in/rdocs/Bulletin/PDFs/04SPB080313F.pdf

2. Srinivas GumparthiSSn, International Journal of Trade, Economics and Finance, Vol. 1, No. 1, June, 2010, Risk Assessment Model for Assessing NBFCs' (Asset Financing) Customers http://www.ijtef.org/papers/22-F453.pdf

3. Srivastava, Smriti, and G. A. R. G. Anchal. "Data mining for credit card risk analysis: a Review." International Journal of Computer Science 3.2 (2013): 193-200.

4. Amita S. Kantawala. Financial Performance Of Non-Banking Finance Companies In India https://pdfs.semanticscholar.org/7d4d/beab6a59377cbb3069568e620d6523b0d1c8.pdf 
5. Viral V. Acharya Hemal Khandwala, The growth of a shadow banking system in emerging markets: Evidence from India https://www.sciencedirect.com/science/article/pii/S0261560613000971

6. Parveen, M., and O. H. Mohideen. "A Study on Financial Performance of Pharmaceutical Company Using Five Power Analyses." International Journal of Business Management \& Research (IJBMR), 1 (4), 4550 (2014).

7. Y.V. REDDY, Credit Rating: Changing Perspectives https://rbidocs.rbi.org.in/rdocs/Bulletin/PDFs/13292.pdf

8. Saibal Ghosh, August 6, 2010, Credit Growth, Bank Soundness and Financial Fragility: Evidence from Indian Banking Sector https://journals.sagepub.com/doi/abs/10.1177/139156141001100105

9. Chaturvedi, Meenakshi. "Borrower Rating Related to Credit Risk in Commercial Banks." International Journal of Accounting and Financial Management Research (IJAFMR) 4.2 (2014): 19-26.

10. Saibal Ghosh, Determinants of Credit Risk in Indian State-owned Banks: An Empirical Investigation https://mpra.ub.unimuenchen.de/id/eprint/17301

11. Sumon Kumar Bhaumik, does lending behaviour of banks in emerging economies vary by ownership? Evidence from the Indian banking sector https://www.sciencedirect.com/science/article/pii/S0939362507000519

12. Y. V. REDDY ,Banking Sector Reforms in India: An Overview https://rbidocs.rbi.org.in/rdocs/Bulletin/PDFs/63675.pdf

13. Derbali, Abdelkader, and Slaheddine Hallara. "Analysis of Default Probability: A Comparative Theoretical Approach between the Credit Portfolio View Model and the Creditrisk Model." International Journal of Business Management \& Research (IJBMR) 3.1 (2013): 157-170.

14. http://www.academia.edu/download/33984664/pap_IJO7__Perceptual_study_of_behavioral_implication_of_usage_of_ICT_for_sustainable_e-Governance_in_Rural_India_(april2012-59).pdf\#page=206

15. https://www.researchgate.net/profile/Somanadevi_Thiagarajan2/publication/293517635_Credit_Risk_Determinants_of_Publi c_and_Private_Sector_Banks_in_India/links/56b9556808ae9d9ac67dd25f/Credit-Risk-Determinants-of-Public-and-PrivateSector-Banks-in-India.pdf

16. http://www.academia.edu/download/33984664/pap_IJ07__Perceptual_study_of_behavioral_implication_of_usage_of_ICT_for_sustainable_e-Governance_in_Rural_India_(april2012-59).pdf\#page=206 